\title{
Geographical Access of the Elderly to Health Care Centers During a 20-Year Period (1996-2016): a Case Study of Kermanshah, Iran
}

J Gen Intern Med 36(10):3249-51

DOI: $10.1007 / \mathrm{s} 11606-020-06289-\mathrm{w}$

() Society of General Internal Medicine 2020

\section{INTRODUCTION}

The growing population of the elderly is a global challenge; $10 \%$ of the world's population is over 65 years of age and is expected to double in the next 40 years. ${ }^{1}$ In developing countries, poor service delivery and inappropriate distribution of health care centers (HCC) is common. The equitable access of all members of society (especially the elderly) to health services can promote health, improve outcomes, and reduce hospitalization. However, imbalance in the geographical distribution of health care centers can lead to the inefficiencies in service delivery and access inequality, and could be one of the causes of health inequity. Our study purpose was to assess walk-time accessibility of elderly patients to $\mathrm{HCC}^{2}$

\section{METHODS}

Our descriptive cross-sectional study sample included all elderly (65 years and older) people in the Kermanshah metropolis area. Using Iranian Statistical Center and Kermanshah Health Center data, we used Geographic Information System (GIS) to assess walking time from the subject's home to the nearest HCC. Given that $750 \mathrm{~m}$ is a considered standard distance for access in $\operatorname{Iran}^{2,3}$ and that a person's walking speed is normally 0.75 to $1.25 \mathrm{~m} / \mathrm{s}$, this translates to $12.5 \mathrm{~min}$ of walking time as being geographically accessible. We calculat-

Received June 24, 2020

Accepted October 5, 2020

Published online October19, 2020 ed these boundaries through real passages using the Network Analysis tool.

\section{RESULTS}

In 1996, Kermanshah metropolis had a population of 693,157 people with 29 health centers; 32,729 elders and $48.15 \%$ did not have proper access to HCC. Between 2006 and 2016, the population and number of HCC increased with a smaller percentage of adults living more than $12.5 \mathrm{~min}$ from the nearest HCC (Table 1). Figure 1 shows the coverage and spatial distribution of health centers at these three time periods. According to the results of the SDE test, the trend of expansion of the city has been to the north-east and south-west while the trend of expansion of $\mathrm{HCC}$ has been towards the north-west and west. At the same time, the trend of expansion of the aging population was to the south and central parts of the Kermanshah metropolis.

\section{DISCUSSION}

We found that walk times to the nearest health center decreased during 1996 to 2016, though by 2016, more than $30 \%$ of the elderly lived farther than 12.5 min from the nearest health center. These results are consistent with other reports, ${ }^{3,4}$ though focused on a different population, the elderly. While walk times have improved, health policies and programs, there are still significant portions of the elderly that have inadequate access to HCC. Elderly people face physical, economic, and discriminatory restrictions as well as lower web-based literacy 
Table 1 Comparison of Appropriate and Inappropriate Access in Elderly Men and Women of Kermanshah During 1996 to 2016

\begin{tabular}{|c|c|c|c|c|c|c|c|}
\hline & & \multicolumn{2}{|l|}{1996} & \multicolumn{2}{|l|}{2006} & \multicolumn{2}{|l|}{2016} \\
\hline & & $N$ & $\%$ & $N$ & $\%$ & $N$ & $\%$ \\
\hline Total population & $\begin{array}{l}\text { Population with appropriate access } \\
\text { Population with inappropriate access } \\
\text { Total }\end{array}$ & $\begin{array}{l}16,971 \\
15,758 \\
32,729\end{array}$ & $\begin{array}{l}51.85 \\
48.15 \\
100\end{array}$ & $\begin{array}{l}20,231 \\
18,561 \\
38,792\end{array}$ & $\begin{array}{l}52.15 \\
47.85 \\
100\end{array}$ & $\begin{array}{l}36,866 \\
20,841 \\
57,707\end{array}$ & $\begin{array}{l}63.88 \\
36.12 \\
100\end{array}$ \\
\hline
\end{tabular}
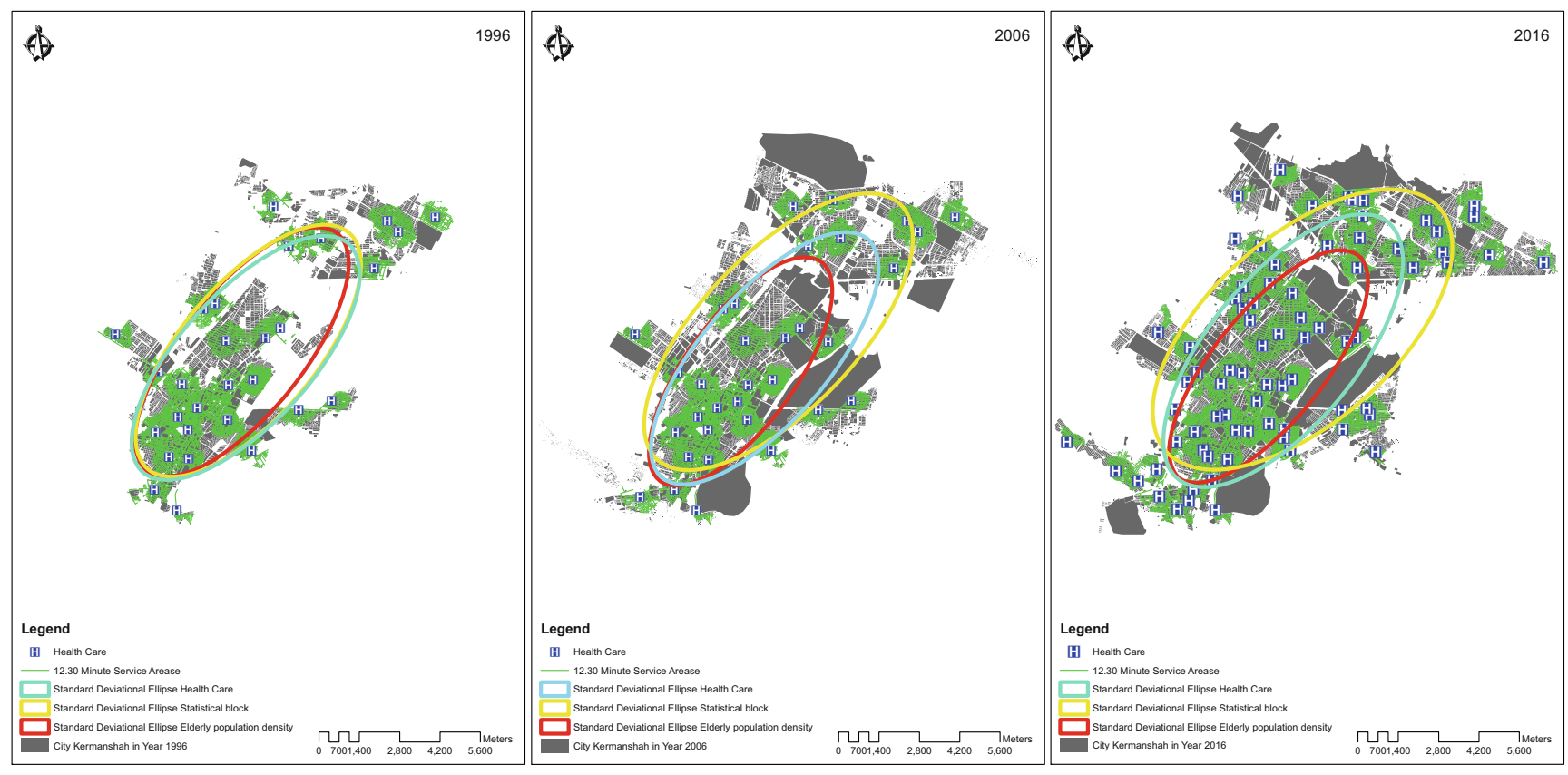

Figure 1 Coverage and spatial distribution of HCC during the period of 1996-2016 
compared with the other age groups, which reduces their access to HCC and can lead to poor health. ${ }^{5}$ This is even more important when the elderly live alone and are socially isolated. ${ }^{6}$ Research is needed on the health impact of longer walk times as well as to other groups such as children or those with disabilities.

Acknowledgments: The authors would like to thank the staff of Kermanshah Health Center, as well as Kermanshah University of Medical Sciences, in providing financial support (Grant No.: 97296, and Ethics Approval No.: IR.KUMS.REC.1397.275).

Ali Almasi, Phd ${ }^{1}$

Shahram Saeidi, $\mathrm{MSc}^{1}$

Alireza Zangeneh, $\mathrm{MSc}^{1}$

Mehdi Khezeli, Phd ${ }^{1}$

Yahya Salimi, Phd ${ }^{1}$

Moslem Soofi, Phd ${ }^{1}$

Nader Rajajbi Gilan, Phd ${ }^{1}$

${ }^{1}$ Social Development and Health Promotion Research Center, Health Institute, Kermanshah University of Medical Sciences,

Kermanshah, Iran

Corresponding Author: Shahram Saeidi, MSc; Social Development and Health Promotion Research Center, Health Institute, Kermanshah University of Medical Sciences, Kermanshah, Iran (e-mail: saedishahram@yahoo.com).

\section{Compliance with Ethical Standards:}

Conflict of Interest: The authors declare that they do not have a conflict of interest.

\section{REFERENCES}

1. The World Bank. World Bank staff estimates based on age/sex distributions of United Nations Population Division's World Population Prospects: 2019 Revision. 2019 [2019/09/21]; Available from: https://data.worldbank.org/ indicator /SP.POP.65UP.TO.ZS?end=2018\&locations=IR\&name desc=false\&start=2006. Accessed 21 Sep 2019.

2. Reshadat S, Saedi S, Zangeneh A, Amooie MR, Karbasi A. Equity in access to health care using geographic information system: a Kermanshah case study. J Mazandaran Univ Med Sci. 2014;24(115):134-40.

3. Reshadat S, Saedi S, Zangeneh A, Ghasemi S, Gilan N, Karbasi A, et al. Spatial accessibility of the population to urban health centres in Kermanshah, Islamic Republic of Iran: a geographic information systems analysis. East Mediterr Health J. 2015;21(6):389-95.

4. Ahadnejad M, Ghaderi H, Hadian M, Haghighatfard P, Darvishi B, Haghighatfard E, et al. Location Allocation of Health Care Centers Using Geographical Information System: Region 11 of Tehran. J Fasa Univ Med Sci/Majallah-i Danishgah-i Ulum-i Pizishki-i Fasa. 2015;4(4):463-74.

5. Organization WH. World report on ageing and health. WHO; 2015 [cited 2020 29/06/2020]; Available from: https://apps.who.int/iris/bitstream/ handle / 10665 / $186463 / 9789240694811$ eng.pdf; jsessionid $=2375 \mathrm{~A} 3 \mathrm{FBE} 6 \mathrm{~F} 81882 \mathrm{D} 8 \mathrm{DA7DA} 27 \mathrm{E} 6 \mathrm{DA56D}$ ? sequence $=1$. Accessed 29 June 2020.

6. Organization WH. Age-friendly PHC centres toolkit. WHO; 2008 [cited 2020 29/06/2020]; Available from: https://www.who.int/ageing/publications/ AF_PHC_Centretoolkit.pdf. Accessed 29 June 2020.

Publisher's Note: Springer Nature remains neutral with regard to jurisdictional claims in published maps and institutional affiliations. 